\title{
Protective efficacy of recombinant wsv477 protein against white spot syndrome virus infection in the tiger shrimp Penaeus monodon
}

\author{
T. G. PUNEETH ${ }^{1}$, D. S. AKHILA², M. M. DECHAMMA³, K. S. SANTHOSH ${ }^{4}$, \\ M. N. VENUGOPAL ${ }^{1}$ AND S. K. GIRISHA ${ }^{1}$ \\ ${ }^{1}$ Department of Aquatic Animal Health Management, College of Fisheries, Mangaluru - 575 002, Karnataka, India \\ ${ }^{2}$ NITTE (Deemed to be University), NITTE University Centre for Science Education and Research (NUCSER) \\ Mangaluru, Karnataka, India \\ ${ }^{3}$ UCD-Centre for Food Safety, School of Public Health, Physiotherapy and Sports Science, University College Dublin \\ Belfield, Dublin D04 N2E5 \\ ${ }^{4}$ Viral and Diagnostic Laboratory (VRDL), Shivamogga Institute of Medical Sciences, Sagar road \\ Shivamogga-577 201, India \\ e-mail:skgirisha@gmail.com
}

\begin{abstract}
White spot syndrome virus (WSSV) is a highly virulent shrimp pathogen reported in almost all the shrimp producing nations causing huge economic loss to the aquaculture industry. In the present study, we investigated the efficacy of a recombinant wsv477 protein against WSSV infection in the tiger shrimp Penaeus monodon by intramuscular and oral administration. The $w s v 477$ is a protein encoded by the non-structural gene $w s v 477$, having a key role in DNA replication and proliferation of guanosine triphosphate (GTP)-binding protein. Non-structural gene wsv477 was amplified from genomic DNA, cloned in PQE30 vector and expressed in Escherichia coli SG cells using isopropyl-1-1-thio-b-d-galactoside (IPTG) inducer. Expression of the recombinant ws 477 protein was confirmed by sodium dodecyl sulphate-polyacrylamide gel electrophoresis (SDS-PAGE) analysis and the purified protein was used for in vivo study. Shrimp immunised with recombinant protein by intramuscular and oral methods showed a cumulative mortality of 40 and $30 \%$ following challenge, respectively. Our findings showed that wsv477 recombinant protein had better protection against WSSV infection when administrated through intramuscular route compared with oral method. Results obtained from this study suggest that ws $v 477$ protein could be used to elicit immune response in P. monodon and for protection against WSSV infection.
\end{abstract}

Keywords: Immune response, Non-structural protein, Penaeus monodon, WSSV, wsv477

\section{Introduction}

Emergence and spread of white spot disease (WSD) caused by white spot syndrome virus (WSSV) remains as a threat to the shrimp aquaculture industries in many developing countries leading to huge economic losses. Since its emergence in 1992, this deadly crustacean pathogen has already spread to most shrimp culturing ecosystems worldwide (Chen, 1992). WSSV is a large, enveloped double-stranded DNA virus having a tail-like appendage at one end. The virus belongs to the genus Whispovirus under the family Nimaviridae (EscobedoBonilla et al., 2008). The genome of WSSV consists of enveloped, circular double-stranded DNA of about $300 \mathrm{~kb}$ with 185 open reading frames (ORFs) (Van Hulten et al., 2001; Yang et al., 2001). This virus infects several species of penaeid shrimps (Rodriguez et al., 2003), causing $100 \%$ mortality within 3-10 days of infection (Karunasagar et al., 1997). WSSV also infects other groups of crustaceans like freshwater prawns, crabs, marine lobsters and crayfish (Jiravanichpaisal, 2001; Chakraborty et al., 2002; Sanchez-Paz 2010; Pradeep et al., 2012).

Apart from the severity of losses due to WSSV infection, lack of effective methods in prevention, treatment and control of WSSV infection is also encountered in the shrimp farming sector. In this regard, it is important to develop an effective method in controlling and minimising the global economic losses due to WSSV infection. Several strategies have been attempted to control WSSV infection such as enhancing the innate immune response using immunostimulants (Vidya, 2016) as well as herbal compounds (Kumaran et al., 2014).

Shrimps lack an accurate adaptive immune system and depend purely on innate immunity to fight against foreign invaders. The quasi immune system in crustaceans is trained to fight against pathogenic infections and it is gaining importance in disease control and prevention in aquaculture sector. Nucleic acid, protein and dsRNA vaccines targeted on various structural proteins of 
WSSV provided promising results in preventing WSSV infection in shrimp (Witteveldt et al., 2004a, b; Robalino et al., 2007; Mu et al., 2012; Yang et al., 2012; Akhila et al., 2015; Puneeth et al., 2017). Most of the studies have targeted the structural protein of WSSV and therefore in this study an attempt was made to target the non-structural protein, wsv477 as an immune candidate to protect shrimp against WSSV infection.

Non-structural protein wsv477 was transcribed at four hour post-infection (hpi) and expressed at six hpi in shrimp. Thus, it was characterised as an early transcribed viral gene encoding 208 amino acid peptides and having a pivotal role in DNA replication and proliferation of GTPbinding protein (Han et al., 2007). These GTP-binding proteins initiate the signaling pathways that could knock on the gene expression and regulation of cell growth and also accountable for mediating the reorganisation of the actin cytoskeleton (Alan, 1998). Studies on the efficiency of $w s v 477$ protein as a candidate in enhancing protection to WSSV is lacking. Hence, the present study focused on the efficacy of $w s v 477$ as a potential candidate to protect P. monodon from WSSV infection.

\section{Materials and methods}

\section{Preparation of virus inoculum}

Shrimps showing characteristic clinical signs of WSSV infection such as white spots on the carapace were sourced from the local farms. Viral inoculum was prepared from the gills and pleopods of WSSV infected shrimp following the method described by Xie et al. (2005). Briefly, the tissues were homogenised in TNE buffer (5 0mM Tris-Cl, $400 \mathrm{mM} \mathrm{NaCl}, 5 \mathrm{mM}$ EDTA; $\mathrm{pH}$ 8.5) and centrifuged at $3500 \mathrm{~g}$ for $5 \mathrm{~min}$ at $4^{\circ} \mathrm{C}$, filtered through nylon net and the supernatant was centrifuged at $30,000 \mathrm{~g}$ for $30 \mathrm{~min}$ at $4^{\circ} \mathrm{C}$. The white pellet was suspended in $10 \mathrm{ml} \mathrm{TN}$ buffer (50 mM Tris- $\mathrm{HCl}, 10 \mathrm{mM} \mathrm{MgCl}, \mathrm{pH}$ 7.5) and centrifuged for $20 \mathrm{~min}$ at $4{ }^{\circ} \mathrm{C}$ followed by re-suspension in $10 \mathrm{ml} \mathrm{TN}$ buffer containing $0.1 \% \mathrm{NaN}_{3}$ and stored at $-80^{\circ} \mathrm{C}$. The WSSV copy number was determined by performing the standard curve experiments by quantitative real-time PCR (data not shown).

\section{Cloning of wsv477 protein}

The full length of wsv477 gene was amplified from the genomic DNA using the designed set of primers, ws $v$ 477-F(5' -CGCGGATCCATGTATATCTTCGTCGAA GG-3') and wsv477-R(5'CGCAAGCTTTTATAAGAAA TGTACAATCCTATGCC-3'), containing restriction sites for BamHI and Hind III enzymes. PCR amplification of the genes was carried out in $30 \mu \mathrm{l}$ reaction mixture having $1 \mathrm{x}$ assay buffer (10 mM Tris- $\mathrm{HCl}, \mathrm{pH} 9.0,1.5 \mathrm{mM} \mathrm{MgCl}_{2}$, $50 \mathrm{mM} \mathrm{KCl}, 0.01 \%$ gelatin), $100 \mu \mathrm{M}$ of each of the four
dNTP's, 10 picomoles of forward and reverse primers and $0.9 \mathrm{U}$ of Taq DNA polymerase (GeNeiTM Merck, Bangalore) and $2 \mu \mathrm{l}$ of template DNA. PCR conditions for the reaction were: Initial denaturation at $95^{\circ} \mathrm{C}$ for $5 \mathrm{~min}$, then 35 cycles of denaturation at $95^{\circ} \mathrm{C}$ for $1 \mathrm{~min}$, annealing at $55^{\circ} \mathrm{C}$ for $1 \mathrm{~min}$, extension at $72^{\circ} \mathrm{C}$ for $1 \mathrm{~min}$ and a final extension at $72^{\circ} \mathrm{C}$ for 10 min was performed using a DNA Engine DYAD (MJ Research, USA) thermo cycler. The PCR product with an amplicon size of $627 \mathrm{bp}$ was visualised in $1.5 \%(\mathrm{w} / \mathrm{v})$ agarose gel. The PCR product of wsv477 was then cloned into PQE30 expression vector and transformed into expression host $E$. coli SG cells. The clones were confirmed for the inserts through PCR using gene and vector specific primers. The positive clones were stored in Luria-Bertani (LB)-glycerol broth containing $100 \mathrm{mg} \mathrm{ml}^{-1}$ ampicillin, $50 \mathrm{mg} \mathrm{ml}^{-1}$ kanamycin and stored at $-80^{\circ} \mathrm{C}$. Cloned product was sent for sequencing and the results were compared with the earlier studies and the sequence was submitted to NCBI GenBank under the Accession number KX388150.

Expression and purification of recombinant wsv477 protein

To determine the expression of recombinant protein, single colony of $E$. coli $\mathrm{SG}$ cells harbouring recombinant plasmid PQE30-wsv477 was grown in LB broth containing $100 \mathrm{mg} \mathrm{ml}^{-1}$ ampicillin, $50 \mathrm{mg} \mathrm{ml}^{-1}$ kanamycin and incubated at $37^{\circ} \mathrm{C}$ in shaker water bath at $100 \mathrm{rpm}$. The expression of recombinant protein was induced using $1 \mathrm{mM}$ final concentration IPTG. Cells were further incubated for $4 \mathrm{~h}$ at $37^{\circ} \mathrm{C}$, harvested by centrifugation and pellets were stored at $-20^{\circ} \mathrm{C}$ until further use. The pellet was thawed at room temperature, mixed with lysis buffer $\left(100 \mathrm{mM} \mathrm{NaH} \mathrm{PO}_{4}, 10 \mathrm{mM}\right.$ Tris-Cl, $6 \mathrm{M}$ Guanidine hydrochloride, $\mathrm{pH}$ 8.0) and sonicated on ice using an ultrasonic processor with 6 cycles of $10 \mathrm{~s}$ pulses and $10 \mathrm{~s}$ rest at $200 \mathrm{~W}$. The supernatant containing recombinant protein was separated by $12 \%$ SDS-PAGE. The recombinant proteins were purified by Ni-NTA affinity chromatography (Qiagen), eluted using elution buffer (100 mM NaH 2 PO4, $10 \mathrm{mM}$ Tris-Cl, Guanidine hydrochloride $6 \mathrm{M}$ with $\mathrm{pH} 4.5$ ), dialysed against Tris buffer $(10 \mathrm{mM}$ Tris $\mathrm{pH} 8.0,0.1 \%$ Triton $\mathrm{X}-100$ ) overnight at $4^{\circ} \mathrm{C}$. The purity of the protein was analysed by $12 \%$ SDS-PAGE and protein was quantified by Lowry's assay (Waterborg and Matthews, 1984). The purified recombinant proteins were then used for the experiments.

\section{Collection of live P. monodon}

Healthy specimens of $P$. monodon (7-10 g) were collected from local farm near Kundapura region, Karnataka, India. The shrimps were maintained in 
fiberglass tanks containing filtered natural seawater having salinity between $20-25 \mathrm{ppt}$, with constant aeration at $28-30^{\circ} \mathrm{C}$. Shrimps were fed with commercial feed $(35 \%$ protein) (CP Feeds, India) at $2 \mathrm{~g}^{\text {bodyweight }}{ }^{-1}$ day $^{-1}$. The physico-chemical parameters of the rearing water were monitored daily. The animals were screened for the presence of major shrimp viruses by polymerase chain reaction (PCR) (Otta et al., 2003) and PCR negative shrimps were used for further experimental study.

\section{Intramuscular administration of recombinant wsv477}

Shrimps were divided in to four groups with 10 animals in each experimental group in triplicates. The shrimps were intramuscularly injected with $100 \mu \mathrm{l}$ of purified recombinant ws 4477 protein between the $2^{\text {nd }}$ and $3^{\text {rd }}$ abdominal segment using a tuberculin syringe. The dose of recombinant purified proteins was determined as $10 \mu \mathrm{g} \mathrm{g}^{-1}$ shrimp based on previous studies. Additionally, a group of animals were injected with plasmid construct having only the promoter and served as plasmid control. Similarly, groups that served as positive and negative controls were injected with $100 \mu$ of sterile PBS. After 10 days of $1^{\text {st }}$ dose administration, shrimps were immunised with a booster dose of same concentration of purified protein while the control groups received same volume of PBS. Shrimps were challenged with $100 \mu$ of WSSV $\left(3.9 \times 10^{5}\right.$ copies $\left.\mu \mathrm{l}^{-1}\right)$ after 15 days of immunisation. The negative control groups were injected with same volume of sterile PBS. The shrimps were monitored daily for mortality and dead shrimps were analysed for presence of WSSV by PCR.

\section{Oral administration of recombinant wsv477}

The recombinant protein wsv477 was expressed in E. coli SG cells for $4 \mathrm{~h}$. The expressed cells containing recombinant protein $w s v 477\left(\mathrm{OD}_{600}=1.0\right)$ were harvested and inactivated in $0.5 \%$ formalin followed by incubation at $20^{\circ} \mathrm{C}$ for $15 \mathrm{~min}$. Inactivated cells were mixed with commercial feed (CP Feeds, India) and coated with cod liver oil by keeping on ice for $15 \mathrm{~min}$ to avoid leaching of the protein (Witteveldt et al., 2004b). Similarly, feed was prepared from $E$. coli $\mathrm{SG}$ cells containing plasmid without recombinant protein and only E. coli SG cells. Shrimps were divided in to four groups with 10 animals in each group, in triplicates. The prepared feeds were fed to the respective groups, twice a day at $2.5 \%$ body weight for 7 days. After 15 days of experimental feeding, shrimps were intramuscularly challenged with $3.9 \times 10^{5}$ copies $\mu \mathrm{l}^{-1}$ of WSSV, shrimps in the negative control group were injected with PBS. Shrimps were monitored regularly and dead shrimps were analysed for WSSV by PCR.

\section{Statistical analyses}

Relative percentage survival (RPS) was calculated as per Amend (1981), to evaluate the protection offered by the recombinant $w s v 477$ protein against WSSV infection:

RPS $=[1-($ Mortality in vaccinated group / Mortality in control group) $] \times 100$.

\section{Results}

\section{PCR amplification of wsv477 gene}

The non-structural gene wsv477 was amplified by PCR from WSSV genomic DNA isolated from WSSV infected shrimp. The resulting PCR product having an amplicon size of $627 \mathrm{bp}$ was visualised in $1.5 \%(\mathrm{w} / \mathrm{v})$ agarose gel (Fig. 1).

\section{Cloning and expression of wsv477 protein}

The amplified wsv477 gene of 647 bp was cloned into an expression vector PQE-30. The clones were confirmed for the inserts by PCR (Fig. 2). The expression of recombinant protein wsv477 was induced with IPTG in E. coli SG cells. The expressed recombinant protein wsv477 of $20 \mathrm{kDa}$ was confirmed by SDS-PAGE (Fig. 3).

\section{Intramuscular administration of recombinant wsv477}

The experimental shrimps that received wsv477 protein, upon challenge with WSSV, showed $70 \%$ survival rate which was significantly higher than the shrimp in control groups (Fig. 4). Control group shrimps showed $100 \%$ mortality by 10 days post-infection (dpi) and the dead shrimps were found positive for WSSV infection by PCR.

\section{Oral administration of recombinant wsv477}

Sixty percent of the shrimps fed with wsv 477 protein incorporated feed, survived on $10^{\text {th }}$ day of viral challenge (Fig. 5). Shrimps in positive control and the groups fed

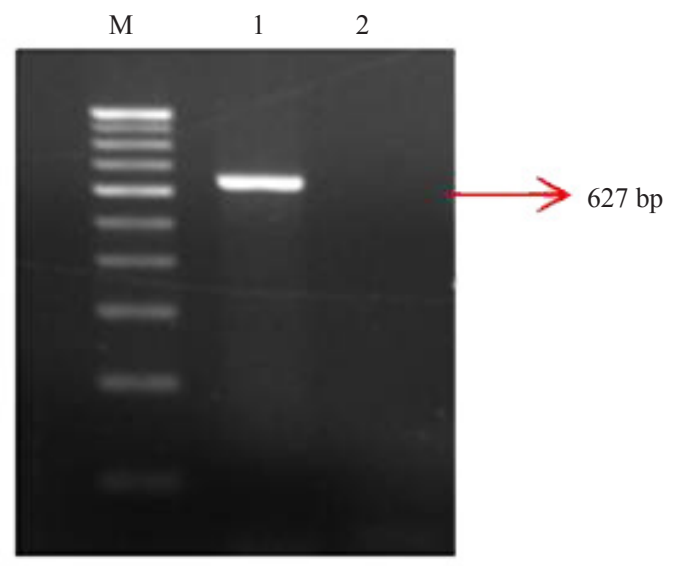

Fig. 1. Agarose gel image showing PCR amplification of wsv477 gene. Lane M: 100 bp DNA ladder; Lane 1: wsv477 gene (627 bp); Lane 2: Negative control 


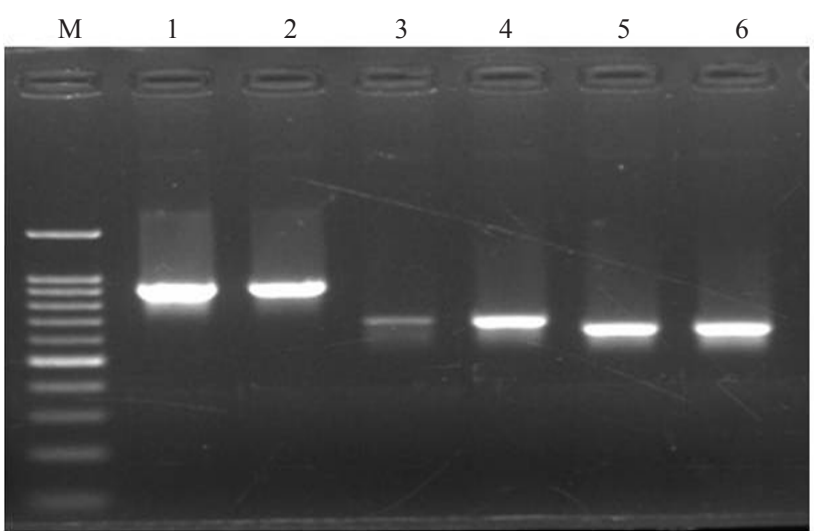

Fig. 2. Agarose gel image showing the PCR amplified clones of wsv477 gene in PQE-30 vector. Lane M: $100 \mathrm{bp}$ DNA ladder; Lane 1-2: Clones amplified using PQE-30 primers; Lane 3-4: Clones amplified using both PQE-30 and wsv 477 primer (F-R); Lane 5-6: Clones amplified by wsv477 primers

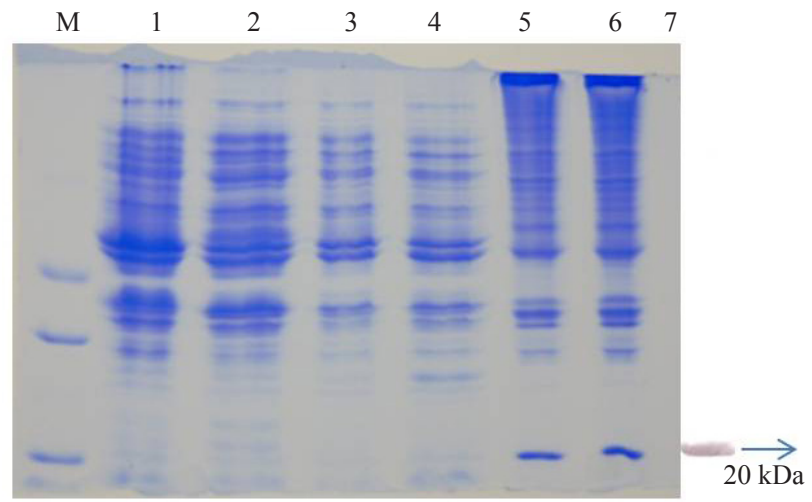

Fig. 3. SDS-PAGE showing the expression of recombinant wsv477 protein

Lane M: Medium range protein ladder; Lane 1-2: Nonrecombinant $E$. coli SG cells without IPTG induction; Lane 3-4: Non-recombinant $E$. coli $\mathrm{SG}$ cells with IPTG induction; Lane 5-6: Recombinant wsv477 clone without IPTG induction; Lane 5-6: Recombinant wsv477 clone with IPTG induction; Lane 7: Purified recombinant $w s v 477$ protein.

SG cells containing no protein, showed $100 \%$ mortality at 10 dpi. All the dead shrimps were PCR positive for WSSV. However, no mortalities were recorded in negative control groups. Compared to oral route of protein delivery, injection route showed higher protection against WSSV infection.

\section{Discussion}

The development of a suitable candidate to afford protection against WSSV was impeded due to limited information about the etiology of the disease. Many researchers have proved a quasi-immune response in shrimp against viral diseases in natural or experimental infection (Venegas, 2000). The results showed that shrimps surviving from initial infection had an increased survival rate (94\%) compared to uninfected shrimps on the second challenge (Venegas et al., 2000; Wu et al., 2002). This study aimed at seeing whether the expressed viral protein $w s v 477$ can elicit an immune response in P. monodon and whether they could protect against WSSV infection. The functional protein was synthesised using recombinant $w s v 477-\mathrm{pQE}-30$ construct and expressed in E. coli cells. Recombinant proteins induce high resistance by delivering into shrimps (Namikoshi et al., 2004). Earlier studies have focused on the envelope protein VP28 as a potential candidate for vaccination in shrimp against WSSV. VP28 gene interacts with host cells in stimulating the protective immune response to exhibit antiviral mechanism in the host (Chang et al., 2008). In our study, we used wsv477 as a candidate protein for protection against WSSV. The gene coding for the non-structural protein, ws $v 477$ transcribed at 4 hpi and expressed at 6 hpi in vivo, respectively having GTP-binding activity that controls the regulation and expression of the late genes (Sanchez-Paz, 2010). Immunisation efficacy of $w s v 477$ protein was studied by administration through intramuscular as well as oral routes. Intramuscular injection is not a practical strategy in shrimp farming; however, it is essential in determining the vaccine potential of the proteins and to ensure the precise amount of protein delivered to each shrimp. Shrimps that received intramuscular delivery showed higher survival rate compared to the orally administered group. All experimental conditions except the mode of administration of recombinant proteins were kept constant for all the groups. Groups immunised by oral mode and injection mode with wsv477 protein showed cumulative moralities of 40 and $30 \%$, respectively. This demonstrated that injection with $w s v 477$ protein offered better protection against WSSV in shrimps than oral administration. These results are in agreement with the findings of $\mathrm{Ha}$ et al. (2008), on the development of injection and oral vaccines against WSSV. The cumulative mortalities reported were 50.2 and $51.8 \%$ in injection and 49.2 and $89.2 \%$ for the oral immunisation by feeding with rVP19 and rVP466, respectively in Penaeus chinensis. The RPS obtained in subunit immunisation was significantly higher than oral immunisation due to their low mucosal permeability, apparent destruction of proteins in the shrimp's digestive tract resulting in degradation of the molecules before absorption. Delivery of vaccines to the target tissue is the major hurdle for successful immunisation. 


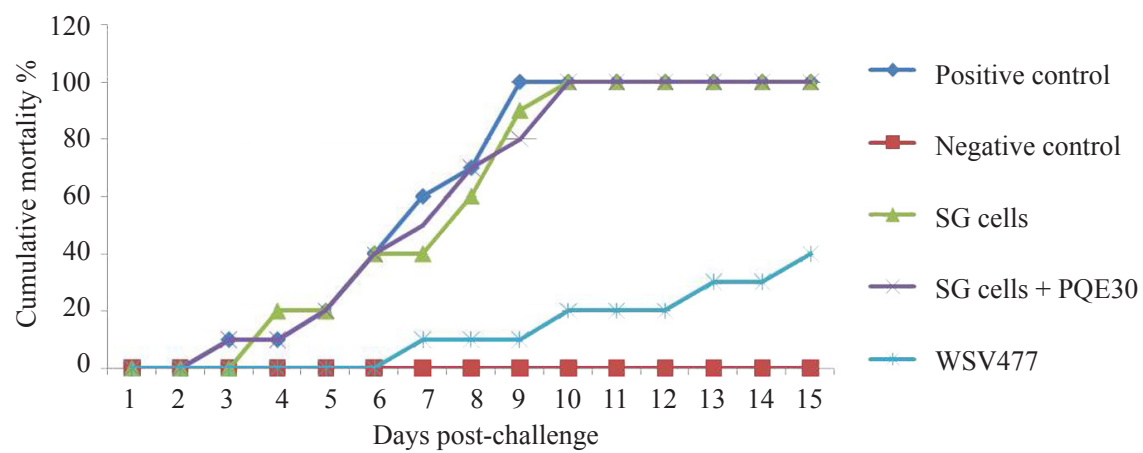

Fig. 4. Cumulative mortality of $P$. monodon immunised with $w s v 477$ protein by intramuscular injection

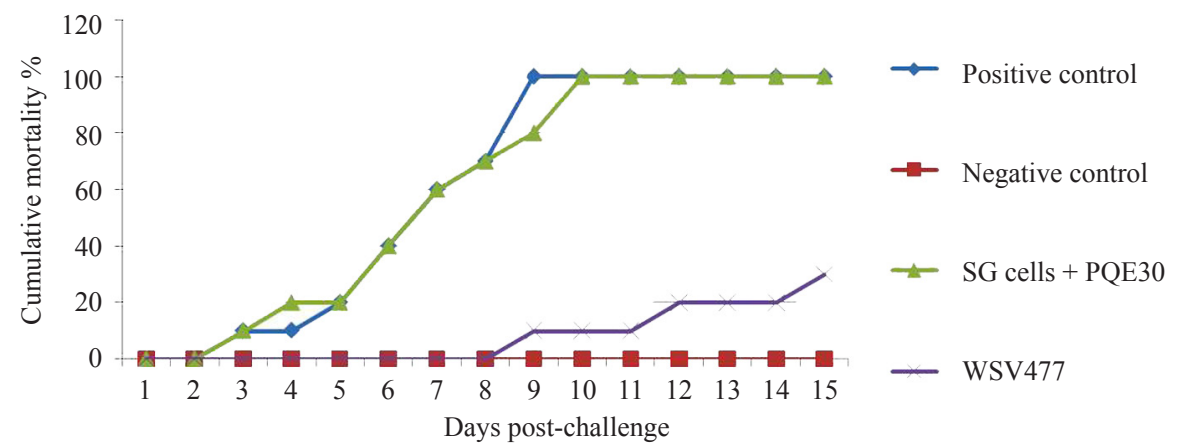

Fig. 5. Cumulative mortality of $P$. monodon immunised with $w s v 477$ protein by oral method

Our findings demonstrated that WSSV non-structural proteins could be potential elements for enhancing protection against WSSV in shrimps. The intramuscular mode of administration provided better protection against WSSV (RPS 70\%) when compared with oral delivery (RPS $60 \%$ ) and the results clearly indicate that recombinant wsv477 could be potential target protein for imparting protection against WSSV infection in $P$. monodon.

\section{Acknowledgements}

This work was carried out under the "National Surveillance Program for Aquatic Animal Diseases" (G/ Nat.Surveillance/2013/5310) funded by the National Fisheries Development Board (NFDB) and Department of Fisheries, Govt. of India. The authors acknowledge the DBT Bioinformatics Centre, College of Fisheries, Mangaluru for support provided in the analysis part.

\section{References}

Akhila, D. S., Rai, P., Mani, M. K., Ballamoole, K. K., Karunasagar, I. and Karunasagar, I. 2015. Protection of Litopenaeus vannamei against white spot syndrome virus using bacterially expressed recombinant envelope proteins VP39 and VP28. Isr. J. Aquac. Bamidgeh, 67.2015.1116.

Alan, H. 1998. Rho GTPases and the actin cytoskeleton. Science, 279: 509-514. doi: 10.1126/science.279.5350.509.

Amend, D. F. 1981. Potency testing of fish vaccines. Devp. Biol. Stand., 49: 447-454.
Chakraborty, A., Otta, S. K., Kumar, B. J. S., Hossain, M. S., Karunasagar, I., Venugopal, M. N. and Karunasagar, I. 2002. Prevalence of white spot syndrome virus in wild crustaceans along the coast of India. Current Science, 82: 1392-1397.

Chang, Y. S., Liu, W. J., Chou, T. L., Lee, Y. T., Lee, T. L., Huang, W. T., Kou, G. H. and Lo, C. F. 2008. Characterisation of white spot syndrome virus envelope protein VP51A and its interaction with viral tegument protein VP26. J. Virol., 82(24): 12555-12564. doi: 10.1128/JVI.01238-08.

Chen, S. N. 1992. Coping with diseases in shrimp farming. In: De Saram, H. and Singh, T. (Eds.), Shrimp '92, Hongkong, Proceedings of the $3^{\text {rd }}$ Global Conference on the shrimp industry, 14-16 September 1992, Hong Kong, p. 113-117.

Escobedo-bonilla, C. M., Alday-Sanz, V., Wille, M., Sorgeloos, P., Pensaert, M. B. and Nauwynck, H. J. 2008. A review on the morphology, molecular characterization, morphogenesis and pathogenesis of white spot syndrome virus. J. Fish. Dis., 31: 1-18. doi: 10.1111/j.1365-2761.2007.00877.x.

Ha, Y. M., Soo, J. G., Thi, H. N., Chae, H. R., Ki, H. K., Yoon, K. N. and Sung, K. K. 2008. Vaccination of shrimp Penaeus chinensis against white spot syndrome virus (WSSV). J. Microbiol. Biotechnol., 18(5): 964-967.

Han, F., Xu, J. and Zhang, X. 2007. Characterization of an early gene (wsv477) from shrimp white spot syndrome virus (WSSV). Virus Genes, 34: 193-198. doi: 10.1007/s11262006-0053-0. 
Jiravanichpaisal, P., Bangyeekhun, E., Soderhall, K. and Soderhall, I. 2001. Experimental infection of white spot syndrome virus in freshwater crayfish, Pacifastacus leniusculus. Dis. Aquat. Org., 47: 151-157. doi: 10.3354/ dao047151.

Karunasagar, I., Otta, S. K. and Karunasagar, I. 1997. Histopathological and bacteriological study of white spot syndrome of Penaeus monodon along the west coast of India. Aquaculture, 153: 9-13. https://doi.org/10.1016/ S0044-8486(97)00011-2.

Kumaran T., Thanga viji, V., Velmurugan S. and Citarasu T. 2014. Influence of selected antiviral herbal active principles against shrimp white spot syndrome virus (WSSV). Int. J. Biochem. Mol., 2: 41-49.

Mu, Y., Lan, J. F., Zhang, X. W., Wang, X. W., Zhao, X. F. and Wang, J. X. 2012. A vector that expresses VP28 of WSSV can protect red swamp crayfish from white spot disease. Dev. Comp. Immunol., 36(2): 442-449. doi: 10.1016/j.dci. 2011.08.009.

Namikoshi, A., Wu, J. L., Yamashita, T., Nishizawa, T., Nishioka, T., Arimoto, M. and Muroga, K. 2004. Vaccination trials with Penaeus japonicus to induce resistance to white spot syndrome virus. Aquaculture, 229: $25 \mathrm{e} 35$.

Otta, S. K., Karunasagar, I. and Karunasagar, I. 2003. Detection of monodon baculovirus and white spot syndrome virus in apparently healthy Penaeus monodon post-larvae from India by polymerase chain reaction. Aquaculture, 220: 59-67. doi:10.1016/S0044-8486(02)00340-X.

Pradeep, B., Rai, P., Mohan, S. A., Shekhar, M. S. and Karunasagar, I. 2012. Biology, host range, pathogenesis and diagnosis of white spot syndrome virus. Indian J. Virol., 23: 161-174. doi: 10.1007/s13337-012-0079-y.

Puneeth,T.G.,Akhila,D.S., Dechamma, M.M., Shreeharsha,J.M., Santhosh K. S. and Venugopal, M. N. 2017. Comparative efficacy of dsRNA VP24, VP26, RR1 and WSV477 gene against WSSV infection in Penaeus monodon. Int. J. Curr. Microbiol. Appl. Sci., 6(2): 665-674. doi: http://dx.doi. org/10.20546/ijcmas.2017.602.075.

Robalino, J., Bartlett, T. C., Chapman, R. W., Gross, P. S., Browdy, C. L. and Warr, G. W. 2007. Double-stranded RNA and antiviral immunity in marine shrimp: Inducible host mechanisms and evidence for the evolution of viral counter-responses. Dev. Comp. Immunol., 31(6): 539-547. doi:10.1016/j.dci.2006.08.011.

Rodriguez, J., Bayot, B., Amano, Y., Panchana, F., De Blas, I., Alday, V. and Caleron, J. 2003. White spot syndrome virus infection in cultured Penaeus vannamei (Boone) in Ecuador with emphasis on histopathology and ultrastructure. J. Fish. Dis., 26: 439-450. doi: 10.1046/j.1365-2761.2003.00483.x.

Sanchez-Paz, A. 2010. White spot syndrome virus: An overview on an emergent concern. Vet. Res., 41(6): 43. doi: 10.1051/ vetres $/ 2010015$

Van Hulten, M. C. W. and Vlak, J. M. 2001. Identification and phylogeny of a protein kinase gene of white spot syndrome virus. Virus Genes, 22: 201-207.

Venegas, C. A., Nonaka, L., Mushiake, K., Nishizawa, T. and Muroga, K. 2000. Quasi-immune response of Penaeus japonicus against penaeid rod-shaped DNA virus (PRDV). Dis. Aquat. Org., 42: 83-89. doi: 10.3354/dao042083.

Vidya, R., Makesh, M., Purushothaman, C. S., Chaudhari, A., Babu, P. and Rajendran, K. V. 2016. Report of leucine-rich repeats (LRRs) from Scylla serrata: Ontogeny, molecular cloning, characterization and expression analysis following ligand stimulation and upon bacterial and viral infections. Gene, 590(1): 159-168. doi: 10.1016/j.gene.2016.06.026.

Waterborg, J. H. and Matthews, H. R. 1984. The Lowry method for protein quantitation. In: Walker, J. M. (Ed.), Methods in molecular biology, vol 1: Proteins. Humana Press, New Jersey, USA. https://doi.org/10.1385/0-89603-062-8:1.

Witteveldt, J., Vlak, J. M. and Van Hulten, M. C. W. 2004a. Protection of Penaeus monodon against white spot syndrome virus using a WSSV subunit vaccine. Fish Shellfish Immunol., 16: 571-579. doi: 10.1016/j.fsi.2003. 09.006.

Witteveldt, J., Cifuentes, C. C., Vlak, J. M. and Van hulten M. C. W. 2004b. Protection of Penaeus monodon against white spot syndrome virus by oral vaccination. J. Virol., 78: 2057-2061. doi: 10.1128/jvi.78.4.2057-2061.2004.

Wu, J. L., Nishioka, T., Mori, K., Nishizawa, T. and Muroga, K. 2002. A time-course study on the resistance of Penaeus japonicus induced by artificial infection with white spot syndrome virus. Fish Shellfish Immunol., 13: 391-403. doi: 10.1006/fsim.2002.0414.

Xie, X., Li, H. Y., Xu, L. M. and Yang, F. 2005. A simple and efficient method for purification of intact white spot syndrome virus (WSSV) viral particles. Virus Res., 108: 63-67. doi: 10.1016/j.virusres.2004.08.002.

Yang, J. Y., Chang, C. I., Liu, K. F., Hseu, J. R., Chen, L. H. and Tsai, J. M. 2012.Viral resistance and immune responses of the shrimp Litopenaeus vannamei vaccinated by two WSSV structural proteins. Immunol. Lett., 148(1): 41-48. doi: 10.1016/j.imlet.2012.08.004.

Yang, F., He, J., Lin, X., Li, Q., Pan, D., Zhang, X. and Xu, X. 2001. Complete genome sequence of the shrimp white spot bacilliform virus. J. Virol., 75: 11811-11820. doi: 10.1128/ JVI.75.23.11811-11820.2001. 